necessary. My experience of local hospital teams is that it is difficult to be placed in a disaster environment when you are used to working in a gynaecological operating theatre.

As Dr Nancekievill says, major accidents occur when least expected, and the best plan is to have available staff who are used to dealing with smaller incidents, are readily available and know the area, and can be on site through the ambulance control centre at very short notice.

A K BUDD

Reading RG6 2HG

Nancekievill DG. Disaster management: practice makes perfect. Br Med f 1989;298:477. (25 February.)

SIR, - May I take issue with Dr D G Nancekievill's statement that "the part played by the mobile team in a major accident plan is not practised."

The south Manchester accident rescue team (SMART) has practised on site management on many occasions. We have regular drills with the local emergency services to ensure that we adhere to recognised protocols while on the scene. Furthermore, we regularly attend victims outside hospital, as do other members of immediate care schemes. I know that some hospitals still have "flying squads" that are an ad hoc arrangement of inexperienced doctors dispatched to the scene of an accident. This, however, is not the case in south Manchester or in many places in the United Kingdom.

Without a central coordinating body each major accident or disaster is managed by people for whom this is likely to be the first and only occasion they will be involved in such an event. The local response will always be required and is extremely important. A core group of experienced rescue workers could, however, be anywhere in the United Kingdom within an hour or two. Their experience would no doubt be of great value to the local rescue team, which would in this way benefit from past experience.

I also take issue with the statement that the mobile team "should consist of as many anaesthetists and gynaecologists as can be spared." It is not the parent specialty that is important but that whoever goes out has had specific training in out of hospital care and previous experience. This may be a gynaecologist in some hospitals, but I doubt if this is common. Anaesthetists are skilled in resuscitation within the hospital, but if they are to be included in the team they need additional training. The British Association for Immediate Care (BASICS) has long recognised this, and the Royal College of Surgeons of Edinburgh has now instituted a diploma in immediate medical care. If anyone is in doubt as to the specific skills required he or she can train for and pass this examination.

The experiences of the south Manchester team in Armenia, Lockerbie, and the south Manchester area have convinced us that Britain needs a central coordinating body to respond to disasters at home and abroad. A core team of rescue workers should be dispatched on a regional basis to ensure that the benefit of past experience can be brought as quickly as possible to the local teams at the scene of a disaster and that at least someone on site is not engaged in a once in a lifetime event.

A D REDMOND

South Manchester Accident and Emergency Service,

University Hospital of South Manchester,

Manchester

1 Nancekievill DG. Disaster management: practice makes perfect. Br Med f 1989;298:477. (25 February.)

\section{Coping with disaster}

SIR, - The problems of documentation at major disasters has been raised both by $\mathrm{Mr} \mathrm{M} \mathrm{J}$ Allen and colleagues ' and at several debriefings in the Queen's
Medical Centre, Nottingham. Incidents of the size of the Kegworth air crash are too large to be handled by one hospital alone, with the consequence of confusion caused by using different sets of casualty documents.

I would like to put the case for using a national casualty card in these circumstances and advocate the production of a civilian version of the military field medical cards F Med 825/826. The F Med 826 is easy to use and is printed on thin card. It is protected from the elements by a plastic envelope (F Med 825), in which it is attached to the casualty. The Royal Army Medical Corps training is aimed at coping with mass casualty situations, and the documentation is tailor made with this in mind.

An additional advantage would be that as doctors and other staff travel around the country in pursuit of their careers they would always be familiar with the major incident documentation. My experience of nearly 20 years of casualty exercises in the Territorial Army is that the accuracy in filling in casualty cards improves with familiarity and constant practice.

T J HAWKINS

Department of Anaesthesia

University Hospital,

Queen's Medical Centre,

Nottingham NG7 2UH

1 Staff of the accident and emergency departments of Derbyshire Royal Infirmary, Leicester Royal Infirmary, and Queen's Medical Centre. Coping with the early stages of the Ml disaster: at the scene and on arrival at hospital. $\mathrm{Br} \mathrm{Med} f$ 1989;298:651-4. (11 March.)

\section{Stress and relapse of breast cancer}

SIR, - The clinical, sociological, and political repercussions of establishing that stress is related to the relapse of breast cancer are so great that the recent study by Dr A J Ramirez and colleagues suggesting this to be the case ${ }^{l}$ must be examined in great detail before this hypothesis can be accepted.

These workers have taken great care with the design of their study. Though matched pairs analysis allows sensitive statistical comparisons of small numbers, they used a group of patients with breast cancer who were biased for variables both known and unknown. The patients who relapsed were heterogenous both for variables that have been identified as markers of poor prognosis - for example, multiple axillary node involvement - and for variables that are yet unidentified, which may include the variable under analysis - stress.

If this group is closely examined for factors known to be associated with early recurrence or a poor prognosis there are several that are not documented. For example, adjuvant radiotherapy is known to reduce the incidence of local recurrence or relapse ${ }^{2}$; adjuvant tamoxifen improves disease free survival in postmenopausal women ${ }^{3}$; central and medial tumours may be associated with undetected disease in the internal mammary lymph nodes ${ }^{4}$; and the presence of oestrogen receptors on the tumour improves the prognosis. None of these variables were controlled in this study.

Of particular concern is the presence of 19 women with unaffected lymph nodes (although how this was determined is not stated) who nevertheless relapsed after primary treatment (the time to relapse of these patients is not stated). This subgroup is surely unusual. Data from the national surgical adjuvant breast and bowel project (NSABP) showed that patients without affected lymph nodes had an $85 \%$ probability of disease free survival at five years, and these patients are usually thought to have an excellent prognosis. ${ }^{6}$ Relapse at an early stage obviously shows that the carcinoma was disseminated at the time of preliminary diagnosis and treatment and suggests that the tumour in this subgroup was particularly aggressive. It is unfortunate that the biological behaviour of breast cancer remains difficult to quantify, but it is none the less most relevant to studies of this type. If the authors are to argue that the crucial difference between the controls and patients was the experience of stress and life difficulties then they must control accurately for all the variables known to affect the prognosis of this disease, and this they do not appear to have done.

JEREMY WOOD O J A GILMORE

R J POPERT

Breast Unit,

St Bartholomew's Hospital,

London EC1A 7BE

1 Ramirez AJ, Craig TKJ, Watson JP, Fentiman IS, North WRS, Rubens RD. Stress and relapse of breast cancer. $B r$ Med $\mathcal{f}$ Rubens RD. Stress and relapse

1989;298:291-3. (4 February.) breast. BrMed $\mathcal{F} 1976 ; 1: 1035-8$

3 Breast Cancer Trials Committee. Adjuvant tamoxifen in the management of operable breast cancer: the Scottish trial. Lancet 1987; ii: 171-5.

4 Haagensen CD. Disease of the breast. 2nd ed. Philadelphia: Saunders, 1971.

5 Croton R, Cooke T, Holt S, George WD, Nicholson R, Griffith $\mathrm{K}$. Oestrogen receptors and survival in early breast cancer. $\mathrm{Br}$ Med f 1981;283:1289-91

6 Fisher B, Bauer M, Wickerman DL, Redmond CK, Fisher ER Relation of numbers of positive axillary nodes to the prognosis Relation of numbers of positive axillary nodes to the prognosis
of patients with primary breast cancer: an NSABP update. of patients with primary $1983 ; 52: 1551-6$.

AUTHORS' REPLY, - The intention in our study was, indeed, to control for all known variables in patients who relapse after treatment of early breast cancer so that the variable of interest-namely, stress - could be studied accurately.

Each relapsing patient was matched with a control for primary treatment, either modified radical mastectomy or a conservation procedure comprising excision biopsy of the tumour, axillary clearance, and radiotherapy. None of the patients or controls who had had a mastectomy received adjuvant radiotherapy. The pairs were matched exactly for adjuvant cytotoxic chemotherapy; none of the patients had had adjuvant tamoxifen. The complete axillary clearance in all patients gave precise information on affected axillary lymph nodes, for which the cases and controls were well matched. Oestrogen receptor state was not used to match all the pairs as some patients had presented initially before measurement of oestrogen receptors was routinely available, but for those pairs in whom the information was available good matching was achieved. More importantly, the pairs were well matched for histological grade of tumour, and oestrogen receptor state and histological grade are strongly related.' Moreover, recent evidence suggests that, at least for patients with unaffected axillary nodes, histological assessment may be a more important prognostic indicator than receptor state. ${ }^{2}$ We did not control for the location of the tumour as, although central and medial tumours may be associated with undetected internal involvement of the lymph nodes, this is of little, if any, prognostic importance. ${ }^{3+}$

Dr Wood and his colleagues express concern at the presence of 19 patients with disease and without affected lymph nodes among 50 consecutive relapses. Despite the so called excellent prognosis of patients with unaffected lymph nodes at least a quarter relapse within 10 years. The median time to relapse for the 19 patients was 48 (range 12-145) months compared with a median time of 28 (range 9-116) months for the 31 patients with affected lymph nodes. There is nothing to suggest that the subgroup with unaffected nodes had particularly aggressive tumours, and anyway they were matched carefully with controls for their clinical and pathological features. None of the patients in the study had clinical, biochemical, or radiological evidence of metastatic spread at the time of the initial diagnosis. 